\title{
Kinerja Pegawai Ditinjau Dari Aspek Kemampuan Intelektual \\ dan Disiplin Kerja Pada Kantor Kecamatan Siantar Sitalasari \\ Kota Pematangsiantar
}

\author{
Grace Endang Pakpahan ${ }^{(1)}$ \\ Dita Permata Sari ${ }^{(2)}$ \\ Novita Butarbutar ${ }^{(3)}$ \\ Sekolah Tinggi Ilmu Ekonomi Sultan Agung ${ }^{(1)(2)(3)}$ \\ gracepakpahan@stiesultanagung.ac.id ${ }^{(1)}$ \\ dp1877018@ gmail.com ${ }^{(2)}$ \\ novita@stiesultanagung.ac.id ${ }^{(3)}$
}

\begin{abstract}
The purpose of this study are to determine the influence of intellectual ability and work decipline on employee performance at Kantor Kecamatan Siantar Sitalasari Kota Pematangsiantar. The research was done by using the design of library and field research. The research method used is the causality method with a qualitative and quantitative approach. The sources of data used in this research are primary and secondary. The population in this study were all employee which amounted to 46 employees. The datawere collected through questionnaire, interviews and documentation. The analysis technique used is qualitative and descriptive quantitative analysis which consists of multiple linear regression, correlation test and test of determination and hypothesis. Theresults of this study can be summarized are the intellectual ability, the work discipline and the employee performance are good. Then the intellectual ability have a positive and significant influence to the employee performance. Next work descipline have a positive and significant influence to the employee performance.
\end{abstract}

Keywords: Intellectual Ability; Work Descipline; Employee Performance

\begin{abstract}
ABSTRAK
Tujuan penelitian ini adalah untuk mengetahui pengaruh kemampuan intelektual dan disiplin kerja terhadap kinerja pegawai pada Kantor Kecamatan Siantar Sitalasari Kota Pematangsiantar. Penelitian ini menggunakan desain penelitian kepustakaan dan penelitian lapangan. Metode penelitian yang digunakan adalah metode kausalitas dengan pendekatan kuantitatif. Jenis data yang digunakan dalam penelitian ini adalah data kualitatif serta data kuantitatif. Sumber data terdiri dari data primer serta data sekunder. Populasi dan sampel yang digunakan dalam penelitian ini adalah pegawai tetap sebanyak 46 orang. Pengumpulan data dilakukan dengan kuesioner, wawancara dan dokumentasi. Teknik analisis yang digunakan adalah analisis deskriptif kualitatif dan deskriptif kuantitatif yang terdiri dari regresi linier berganda, uji korelasi dan uji determinasi serta hipotesis. Hasil penelitian ini menyimpulkan kemampuan intelektual, disipilin kerja dan kinerja pegawai sudah baik. Kemudian Kemampuan Intelektual berpengaruh positif dan signifikan terhadap kinerja pegawai. Selanjutnya Disiplin kerja berpengaruh positif dan signifikan terhadap kinerja pegawai.
\end{abstract}

Kata kunci: Kemampuan Intelektual; Disiplin Kerja; Kinerja Pegawai 


\section{PENDAHULUAN}

Perusahaan dikatakan baik apabila memiliki aset yang berupa sumber daya manusia yang berkualitas dan berformansi optimal dalam menjalankan kegiatan di perusahaan agar tujuan perusahaan tercapai (Sahir et al., 2020). Perubahan global utama dalam berbagai domain diikuti oleh perubahan dramatis pada tujuan, nilai, dan praktik organisasi bisnis. Beberapa perubahan penting telah terjadi melibatkan pergeseran ke kerja tim, meningkatnya kebutuhan akan inovasi, dan peningkatan pentingnya intangible seperti pengetahuan, sumber daya intelektual manusia (Goyal and Akhilesh, 2008). Sumber daya manusia merupakan asset paling berharga yang dimiliki oleh suatu organisasi, karena kebenarannya sangat menentukan keberhasilan suatu organisasi. Oleh sebab itu, banyak organisasi yang selalu berusaha meningkatkan kualitas sumber dayanya agar dapat menjalankan aktivitas kerja dengan maksimal. Kantor Kecamatan Siantar Sitalasari Kota Pematangsiantar adalah suatu instansi pemerintahan yang taat akan kedisiplinan. Kinerja pegawai merupakan hal yang sangat penting untuk diperhatikan oleh setiap organisasi, karena aspek-aspek yang terdapat di dalam kinerja pegawai akan memberikan dampak secara keseluruhan bagi tercapainya tujuan suatu organisasi.

Peningkatan kerja pegawai bukanlah pekerjaan yang mudah untuk diterapkan sehingga perlu adanya stimulus tertentu untuk menumbuhkan kesadaran para pekerja agar konsisten meningkatkan kinerjanya (Istiqomah and Suhartini, 2016). Demi mencapai tujuan perusahaan dan organisasi, maka perlu ada tindakan yang konkret untuk selalu meningkatkan kinerja karyawan dan pegawai salah satunya dengan mewujudkan dan memberikan kepuasan kerja (Isvandiari and Idris, 2018). Berdasarkan wawancara survei diperoleh fenomena kinerja pegawai pada Kantor Kecamatan Siantar Sitalasari Kota Pematangsiantar diketahui bahwa kinerja pegawai masih belum optimal. Hal ini dapat dilihat masih adanya persentase dengan kategori tidak baik sebesar 5\% dan kategori cukup baik sebesar 20\%. Dimensi sasaran kerja pegawai, dimana masih ada pegawai yang tidak tepat waktu dalam melaksanakan tugas yang diberikan dan masih menunda-nunda pekerjaan yang dibebankan kepadanya.

Kemampuan intelektual yang lebih rendah dapat mempengaruhi kapasitas individu untuk mengantisipasi dan memahami konsekuensi tindakannya, dan itu bisa berkontribusi pada perencanaan yang buruk, yang mungkin ada kaitannya dengan kemungkinan berakhirnya masa depan dan perencanaan manajemen resiko yang sukses (Umbrasas, 2018). Lebih khusus, kompetensi Intelektual mendalilkan bahwa sifat kepribadian Conscientiousness (terutama melalui usaha yang gigih dan ambisius) dan keterbukaan atau intelektual (terutama melalui 
minat intrinsik dan intelektual rasa ingin tahu) memiliki efek motivasi pada perkembangan dasar perilaku intelektual dan akuisisi pengetahuan (Chamorro-Premuzic, Quiroga and Colom, 2009). Fenomena kemampuan intelektual yang belum optimal pada Kantor Kecamatan Siantar Sitalasari Kota Pematangsiantar Terjado oada dimensi pemahaman verbal, hal ini ditunjukkan dengan masih ada beberapa pegawai yang kurang mampu menyampaikan pendapatnya di dalam organisasi. Pada dimensi penalaran deduktif, terlihat beberapa pegawai kurang tanggap dalam melaksanakan pekerjaan yang diberikan oleh atasannya sehingga menghambat kinerja.

Pada hakikatnya disiplin kerja dapat menumbuhkan kesadaran bagi para pekerja untuk melakukan tugas dengan baik dan benar (Harlie, 2012). Representatif bentuk pengendalian karyawan dan pegawai dalam menjalankan standar organisasi terlihat dari efektivitas disiplin kerja yang dilakukan (Isvandiari and Idris, 2018). Sesuai dengan Peratura Pemerintah No. 53 tahun 2010, disiplin kerja. Fenomena disiplin kerja pada Kantor Kecamatan Siantar Sitalasari Kota Pematangsiantar belum optimal. Hal ini dapat dilihat dari dimensi menajalankan kewajiban, dimana masih terdapat pegawai yang sering dating terlambat dan pulang lebih awal dari ketentuan jam kerja. Selain itu pada dimensi menjauhi larangan terlihat pegawai masih sering menjadi perantara dalam suaru permasalahan demi mendapatkan keuntungan pribadi.

\section{Kemampuan Intelektual}

Dalam melakukan berbagai aktivitas sehari-hari, setiap individu menggunakan pemikiran intelektualnya. Menurut Widodo (2012), kecerdasan intelektual adalah kemampuan intelektual, analisa, logika, dan rasio. Kecerdasan ini merupakan kecerdasan untuk menerima, menyimpan, dan mengolah informasi menjadi fakta. Sedangkan menurut Sutrisno (2011), kemampuan intelektual merupakan kemampuan yang diperlukan untuk menjalankan kegiatan mental. Selanjutnya kemampuan intelektual dapat diukur dengan indikator (Robbins 2003), antara lain kecerdasan numerik, pemahaman verbal, kecepatan perseptual, penalaran induktif, penalaran deduktif, visualisasi, memori.

\section{Disiplin}

Disiplin kerja bagian dari fungsi operasional MSDM yang terpenting karna semakin baik disiplin pegawai, semakin tinggi prestasi kerja yang dicapainya. Tanpa disiplin pegawai yang baik, sulit bagi suatu organisasi untuk mencapai hasil yang optimal. Secara terminilogis, kata disiplin berasal dari kata "Disciplina" yang berarti pengajaran, pelatihan dan sebagainya. Menurut Sutrisno (2009), “disiplin adalah sikap kesediaan dan kerelaan seseorang untuk mematuhi dan menaati norma-norma peraturan yang berlaku di sekitarnya. Sedangkan menurut 
Rivai (2005), disiplin kerja adalah suatu alat yang digunakan para manajer untuk berkomunikasi dengan pegawai agar mereka bersedia untuk mengubah suatu perilaku serta sebagai suatu upaya untuk meningkatkan kesadaran dan kesediaan seseoarang mentaati semua peraturan perusahan dan norma-norma sosial yang berlaku. Dalam meningkatkan disiplin, maka ada kewajiban yang harus dijalankan Pegawai Negeri Sipil (PNS) dan juga laranganlarangan yang harus dihindari.

\section{Kinerja Pegawai}

Kinerja pegawai merupakan hasil dari pekerjaan yang telah dilakukan oleh seorang pegawai dalam rangka mencapai tujuan dari suatu organisasi. Menurut Zainal, et. al. (2015), "kinerja adalah salah satu fungsi yang termasuk dalam motivasi dan kemampuan". Sedangkan menurut Dessler (2006), kinerja adalah prestasi aktual karyawan atau pegawai dibandingkankan dengan prestasi yang diharapkan dari karyawan atau pegawai. Sedangkan berdasarkan PP Nomor 46 tahun 2011 tentang Penilaian Prestasi Kerja PNS, dimensi penilaian kinerja pegawai didasarkan pada sasaran kereja pegawai dan perilaku kerja.

\section{METODE PENELITIAN}

Dalam penelitian ini, penulis menggunakan desain penelitian kepustakaan dan lapangan. Metode penelitian yang digunakan adalah metode kausalitas dengan pendekatan kuantitatif. Objek penelitian adalah Pegawai Negeri Sipil (PNS) Kantor Kecamatan Siantar Sitalasari Kota Pematangsiantar. Jenis data yang digunakan adalah data kualitatif dan kuantitatif. Sumber data berasal dari data primer dan data sekunder. Data penelitian dikumpulkan dengan melakukan wawancara, dokumentasi dan penyebaran kuesioner. Analisis data meliputi analisis data kualitatif dan analisis kuantitatif.

\section{HASIL DAN PEMBAHASAN}

\section{Uji Validitas}

Pengujian validitas pada setiap pertanyaan kuesioner dilakukan dengan cara membandingkan $\mathrm{r}_{\text {kritis }}$ dengan $\mathrm{r}_{\text {hitung }}$ maka pertanyaan pada kuesioner tersebut dapat mengukur yang ingin diukur (valid). Syarat untuk dianggap memenuhi valid adalah jika $r_{\text {hitung }}>r_{\text {kritis }} 0,3$. Berikut ini disajikan hasil perhitungan validitas data: 
Tabel 1. Hasil Uji Validitas

\begin{tabular}{|c|c|c|c|c|c|}
\hline \multicolumn{2}{|c|}{ Variabel } & $\begin{array}{c}\text { Butir } \\
\text { Instrument }\end{array}$ & $\mathbf{r}$ hitung & $\mathbf{r}_{\text {kritis }}$ & Keterangan \\
\hline \multirow{21}{*}{$\begin{array}{l}\text { Kemampuan } \\
\text { Intelektual } \\
\left(\mathrm{X}_{1}\right)\end{array}$} & \multirow{3}{*}{$\begin{array}{l}\text { 1. Kemahiran } \\
\text { Numerik }\end{array}$} & $\mathrm{X} 1.1$ & $\mathbf{0 , 3 6 3}$ & 0,3 & Valid \\
\hline & & $\mathrm{X} 1.2$ & 0,496 & 0,3 & Valid \\
\hline & & $\mathrm{X} 1.3$ & 0,416 & 0,3 & Valid \\
\hline & \multirow{3}{*}{$\begin{array}{l}\text { 2. Kemampuan } \\
\text { Verbal }\end{array}$} & $\mathrm{X} 1.4$ & 0,519 & 0,3 & Valid \\
\hline & & $\mathrm{X} 1.5$ & 0,380 & 0,3 & Valid \\
\hline & & $\mathrm{X} 1.6$ & 0,441 & 0,3 & Valid \\
\hline & \multirow{3}{*}{$\begin{array}{l}\text { 3. Kecepatan } \\
\text { Perseptual }\end{array}$} & $\mathrm{X} 1.7$ & $\mathbf{0 , 5 5 1}$ & 0,3 & Valid \\
\hline & & $\mathrm{X} 1.8$ & $\mathbf{0 , 4 3 9}$ & 0,3 & Valid \\
\hline & & $\mathrm{X} 1.9$ & 0,471 & 0,3 & Valid \\
\hline & \multirow{3}{*}{$\begin{array}{l}\text { 4. Penalaran } \\
\text { Induktif }\end{array}$} & $\mathrm{X} 1.10$ & $\mathbf{0 , 5 2 7}$ & 0,3 & Valid \\
\hline & & $\mathrm{X} 1.11$ & $\mathbf{0 , 5 8 3}$ & 0,3 & Valid \\
\hline & & $\mathrm{X} 1.12$ & 0,482 & 0,3 & Valid \\
\hline & \multirow{3}{*}{$\begin{array}{l}\text { 5. Penalaran } \\
\text { Deduktif }\end{array}$} & $\mathrm{X} 1.13$ & 0,449 & 0,3 & Valid \\
\hline & & X1.14 & $\mathbf{0 , 3 6 3}$ & 0,3 & Valid \\
\hline & & $\mathrm{X} 1.15$ & 0,498 & 0,3 & Valid \\
\hline & \multirow{3}{*}{$\begin{array}{l}\text { 6. Visualisasi } \\
\text { ruangan }\end{array}$} & X1.16 & $\mathbf{0 , 4 9 7}$ & 0,3 & Valid \\
\hline & & $\mathrm{X} 1.17$ & 0,433 & 0,3 & Valid \\
\hline & & X1.18 & 0,550 & 0,3 & Valid \\
\hline & \multirow{3}{*}{ 7. Memori } & $\mathrm{X} 1.19$ & 0,541 & 0,3 & Valid \\
\hline & & $\mathrm{X} 1.20$ & 0,431 & 0,3 & Valid \\
\hline & & $\mathrm{X} 1.21$ & $\overline{0,451}$ & 0,3 & Valid \\
\hline \multirow{31}{*}{$\begin{array}{c}\text { Disiplin Kerja } \\
\qquad\left(\mathrm{X}_{2}\right)\end{array}$} & \multirow{17}{*}{$\begin{array}{l}\text { 1. Menjalankan } \\
\text { kewajiban }\end{array}$} & $\mathrm{X} 2.1$ & 0,680 & 0,3 & Valid \\
\hline & & $\mathrm{X} 2.2$ & 0,575 & 0,3 & Valid \\
\hline & & $\mathrm{X} 2.3$ & 0,625 & 0,3 & Valid \\
\hline & & $\mathrm{X} 2.4$ & 0,554 & 0,3 & Valid \\
\hline & & $\mathrm{X} 2.5$ & 0,497 & 0,3 & Valid \\
\hline & & $\mathrm{X} 2.6$ & 0,698 & 0,3 & Valid \\
\hline & & $\mathrm{X} 2.7$ & $\mathbf{0 , 5 8 8}$ & 0,3 & Valid \\
\hline & & $\mathrm{X} 2.8$ & 0,641 & 0,3 & Valid \\
\hline & & $\begin{array}{l}\mathrm{X} 2.9 \\
\end{array}$ & 0,599 & 0,3 & Valid \\
\hline & & $\mathrm{X} 2.10$ & 0,500 & 0,3 & Valid \\
\hline & & $\mathrm{X} 2.11$ & 0,356 & 0,3 & Valid \\
\hline & & $\mathrm{X} 2.12$ & 0,393 & 0,3 & Valid \\
\hline & & $\mathrm{X} 2.13$ & 0,419 & 0,3 & Valid \\
\hline & & $\mathrm{X} 2.14$ & $\overline{0,586}$ & 0,3 & Valid \\
\hline & & $\mathrm{X} 2.15$ & 0,516 & 0,3 & Valid \\
\hline & & $\mathrm{X} 2.16$ & $\mathbf{0 , 5 8 5}$ & 0,3 & Valid \\
\hline & & X2.17 & $\mathbf{0 , 3 2 3}$ & 0,3 & Valid \\
\hline & \multirow{14}{*}{$\begin{array}{l}\text { 2. Menjauhi } \\
\text { larangan }\end{array}$} & X2.18 & 0,451 & 0,3 & Valid \\
\hline & & X2.19 & $\mathbf{0 , 4 3 4}$ & 0,3 & Valid \\
\hline & & $\mathrm{X} 2.20$ & $\mathbf{0 , 5 5 8}$ & 0,3 & Valid \\
\hline & & $\mathrm{X} 2.21$ & 0,428 & 0,3 & Valid \\
\hline & & $\mathrm{X} 2.22$ & 0,530 & 0,3 & Valid \\
\hline & & $\mathrm{X} 2.23$ & 0,511 & 0,3 & Valid \\
\hline & & $\mathrm{X} 2.24$ & 0,501 & 0,3 & Valid \\
\hline & & $\mathrm{X} 2.25$ & 0,503 & 0,3 & Valid \\
\hline & & X2.26 & $\mathbf{0 , 5 3 0}$ & 0,3 & Valid \\
\hline & & X2.27 & $\mathbf{0 , 5 3 1}$ & 0,3 & Valid \\
\hline & & $\mathrm{X} 2.28$ & 0,637 & 0,3 & Valid \\
\hline & & X2.29 & 0,636 & 0,3 & Valid \\
\hline & & $\mathrm{X} 2.30$ & 0,603 & 0,3 & Valid \\
\hline & & $\mathrm{X} 2.31$ & 0,610 & 0,3 & Valid \\
\hline
\end{tabular}




\begin{tabular}{|c|c|c|c|c|c|}
\hline \multicolumn{2}{|c|}{ Variabel } & $\begin{array}{c}\text { Butir } \\
\text { Instrument }\end{array}$ & $\mathbf{r}$ hitung & $\mathbf{r}$ kritis & Keterangan \\
\hline & & X2.32 & 0,610 & 0,3 & Valid \\
\hline \multirow{20}{*}{$\begin{array}{c}\text { Kinerja } \\
\text { Pegawai (Y) }\end{array}$} & \multirow{8}{*}{$\begin{array}{l}\text { 1. Sasaran Kerja } \\
\text { Pegawai }\end{array}$} & Y.1 & 0,355 & 0,3 & Valid \\
\hline & & Y.2 & 0,407 & 0,3 & Valid \\
\hline & & Y.3 & 0,454 & 0,3 & Valid \\
\hline & & Y.4 & 0,504 & 0,3 & Valid \\
\hline & & Y.5 & 0,343 & 0,3 & Valid \\
\hline & & Y.6 & 0,428 & 0,3 & Valid \\
\hline & & Y.7 & 0,497 & 0,3 & Valid \\
\hline & & Y.8 & 0,505 & 0,3 & Valid \\
\hline & \multirow{12}{*}{ 2. Perilaku Kerja } & Y.9 & 0,433 & 0,3 & Valid \\
\hline & & Y.10 & 0,404 & 0,3 & Valid \\
\hline & & Y.11 & 0,431 & 0,3 & Valid \\
\hline & & Y.12 & 0,464 & 0,3 & Valid \\
\hline & & Y.13 & 0,435 & 0,3 & Valid \\
\hline & & Y.14 & 0,521 & 0,3 & Valid \\
\hline & & Y.15 & 0,579 & 0,3 & Valid \\
\hline & & Y.16 & 0,501 & 0,3 & Valid \\
\hline & & Y.17 & 0,422 & 0,3 & Valid \\
\hline & & Y.18 & 0,438 & 0,3 & Valid \\
\hline & & Y.19 & 0,515 & 0,3 & Valid \\
\hline & & Y.20 & 0,492 & 0,3 & Valid \\
\hline
\end{tabular}

Sumber: hasil pengolahan kuesioner dengan SPSS versi 21 (2019)

\section{Uji Reliabilitas}

Nilai koefisien reliabilitas dikatakan reliable jika Cronbach's Alpha if item Deleted > nilai Cronbach Alpha sebesar 0,70. Adapun hasil uji reliabilitas dalam penelitian ini dapat dilihat dari tabel berikut:

Tabel 2. Hasil Uji Reliabilitas

\begin{tabular}{|c|c|c|c|c|c|}
\hline \multicolumn{2}{|c|}{ Variabel } & \multirow{2}{*}{$\begin{array}{c}\begin{array}{c}\text { Butir } \\
\text { Instrumen }\end{array} \\
\mathrm{X} 1.1\end{array}$} & \multirow{2}{*}{$\begin{array}{c}\text { Cronbac } \\
\text { h's } \\
\text { Alpha if } \\
\text { item } \\
\text { Deleted } \\
0,955\end{array}$} & \multirow{2}{*}{$\begin{array}{c}\text { Cronbac } \\
\text { h Alpha }\end{array}$} & \multirow{2}{*}{$\begin{array}{c}\text { Keterangan } \\
\text { Reliabel }\end{array}$} \\
\hline \multirow{16}{*}{$\begin{array}{c}\text { Kemampuan } \\
\text { Intelektual } \\
\left(\mathrm{X}_{1}\right)\end{array}$} & \multirow{3}{*}{$\begin{array}{l}\text { 1. Kemahiran } \\
\text { Numerik }\end{array}$} & & & & \\
\hline & & $\mathrm{X} 1.2$ & 0,955 & 0,70 & Reliabel \\
\hline & & X1.3 & 0,955 & 0,70 & Reliabel \\
\hline & \multirow{3}{*}{$\begin{array}{l}\text { 2. Kemampuan } \\
\text { Verbal }\end{array}$} & X1.4 & 0,955 & 0,70 & Reliabel \\
\hline & & $\mathrm{X} 1.5$ & 0,955 & 0,70 & Reliabel \\
\hline & & X1.6 & 0,955 & 0,70 & Reliabel \\
\hline & \multirow{3}{*}{$\begin{array}{l}\text { 3. Kecepatan } \\
\text { Perseptual }\end{array}$} & X1.7 & 0,955 & 0,70 & Reliabel \\
\hline & & X1.8 & 0,955 & 0,70 & Reliabel \\
\hline & & X1.9 & 0,955 & 0,70 & Reliabel \\
\hline & \multirow{3}{*}{$\begin{array}{l}\text { 4. Penalaran } \\
\text { Induktif }\end{array}$} & $\mathrm{X} 1.10$ & 0,955 & 0,70 & Reliabel \\
\hline & & $\mathrm{X} 1.11$ & 0,955 & 0,70 & Reliabel \\
\hline & & $\mathrm{X} 1.12$ & 0,955 & 0,70 & Reliabel \\
\hline & \multirow{3}{*}{$\begin{array}{l}\text { 5. Penalaran } \\
\text { Deduktif }\end{array}$} & $\mathrm{X} 1.13$ & 0,955 & 0,70 & Reliabel \\
\hline & & $\mathrm{X} 1.14$ & 0,956 & 0,70 & Reliabel \\
\hline & & $\mathrm{X} 1.15$ & 0,955 & 0,70 & Reliabel \\
\hline & & $\mathrm{X} 1.16$ & 0,955 & 0,70 & Reliabel \\
\hline
\end{tabular}


Jurnal Manajemen Bisnis

Volume 17, No. 2, April 2020
ISSN : 1829-8486 (print) | ISSN : 2528-1216 (online) http://journal.undiknas.ac.id/index.php/magister-manajemen/

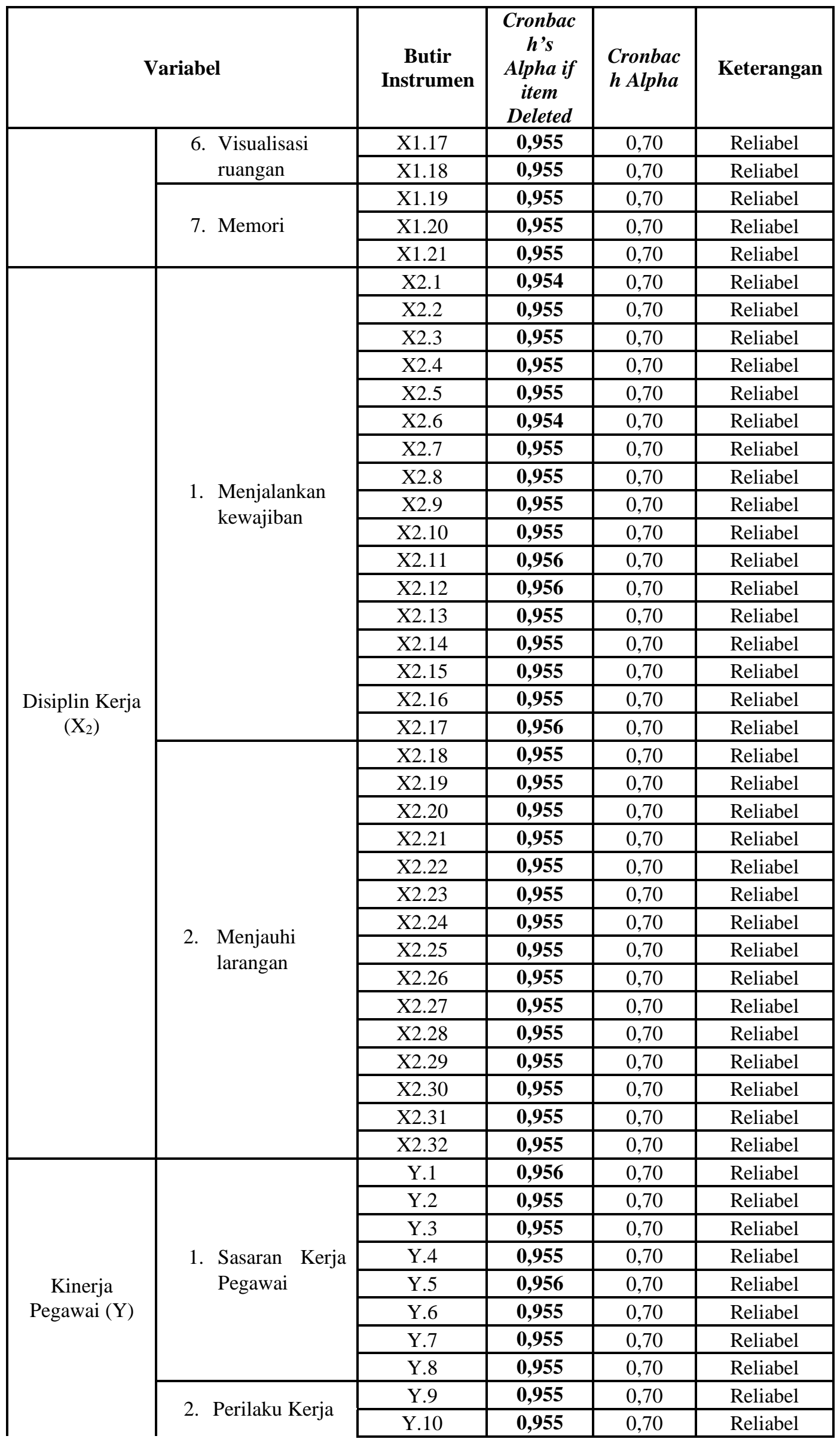




\begin{tabular}{|l|c|c|c|c|c|}
\hline \multicolumn{2}{|c|}{ Variabel } & $\begin{array}{c}\text { Cronbac } \\
\text { Butir } \\
\text { Instrumen }\end{array}$ & $\begin{array}{c}\text { h's } \\
\text { Alpha if } \\
\text { item } \\
\text { Deleted }\end{array}$ & $\begin{array}{c}\text { Cronbac } \\
\text { h Alpha }\end{array}$ & Keterangan \\
\hline \multirow{5}{*}{} & & Y.11 & $\mathbf{0 , 9 5 5}$ & 0,70 & Reliabel \\
\cline { 3 - 6 } & & Y.12 & $\mathbf{0 , 9 5 5}$ & 0,70 & Reliabel \\
\cline { 3 - 6 } & Y.13 & $\mathbf{0 , 9 5 5}$ & 0,70 & Reliabel \\
\cline { 3 - 6 } & Y.14 & $\mathbf{0 , 9 5 5}$ & 0,70 & Reliabel \\
\cline { 3 - 6 } & Y.15 & $\mathbf{0 , 9 5 5}$ & 0,70 & Reliabel \\
\cline { 3 - 6 } & Y.16 & $\mathbf{0 , 9 5 5}$ & 0,70 & Reliabel \\
\cline { 3 - 6 } & Y.17 & $\mathbf{0 , 9 5 5}$ & 0,70 & Reliabel \\
\cline { 3 - 6 } & Y.18 & $\mathbf{0 , 9 5 5}$ & 0,70 & Reliabel \\
\cline { 3 - 6 } & Y.19 & $\mathbf{0 , 9 5 5}$ & 0,70 & Reliabel \\
\cline { 3 - 6 } & Y.20 & $\mathbf{0 , 9 5 5}$ & 0,70 & Reliabel \\
\hline
\end{tabular}

Sumber: hasil pengolahan kuesioner dengan SPSS versi 21 (2019)

\section{Uji Normalitas}

Uji normalitas menggunakan uji Kolmogorov-Smirnov. Teknik yang digunakan untuk menghitung reliabilitas menggunakan bantuan SPSS (Statistical Product and Service Solutions) versi 19. Dari hasil tabel One-Sample Kolmogorov-Smirnov Test maka diperoleh angka probabilitas atau Asym. Sig (2-tailed).

\section{Tabel 3. Hasil Uji Normalitas}

\begin{tabular}{|c|c|c|c|c|c|}
\hline & & $\begin{array}{c}\text { Kemampuan } \\
\text { Intelektual } \\
\text { (X1) }\end{array}$ & \begin{tabular}{c}
\multicolumn{2}{c}{ Disiplin } \\
Kerja
\end{tabular} & $\begin{array}{c}\text { Kinerja } \\
\text { Pegawai } \\
\text { (Y) }\end{array}$ & Total \\
\hline \multirow[t]{2}{*}{$N$} & & 46 & 46 & 46 & 46 \\
\hline & Mean & 79,65 & 119,57 & 74,09 & 273,30 \\
\hline \multirow[t]{2}{*}{ Normal Parametersa, $b$} & Std. Deviation & 8,769 & 14,474 & 8,118 & 28,564 \\
\hline & Absolute &, 114 &, 150 &, 135 & , 137 \\
\hline \multirow{2}{*}{$\begin{array}{l}\text { Most Extreme } \\
\text { Differences }\end{array}$} & Positive &, 114 &, 150 &, 124 & ,137 \\
\hline & Negative &,- 080 &,- 080 &,- 135 &,- 110 \\
\hline Kolmogorov-Smirnov $Z$ & & ,774 & 1,015 & ,916 & ,926 \\
\hline Asymp. Sig. (2-tailed) & &, 587 & ,255 & ,371 & ,358 \\
\hline
\end{tabular}

Sumber: hasil pengolahan kuesioner dengan SPSS versi 21 (2019)

Berdasarkan tabel 3 di atas dapat dilihat Asymp. Sig (2-tiled) pada total $\mathrm{X}_{1}$ (kemampuan intelektual) sebesar 0,587, dan total $\mathrm{X}_{2}$ (disiplin kerja) sebesar 0,255 dan total Y (kinerja pegawai) sebesar 0,371, serta total keseluruhan 0,358 memiliki nilai Asymp. Sig (2-tailed) lebih besar dari alpha 0,05. Dengan demikian dapat dinyatakan bahwa masing-masing data variabel berdistribusi normal. 


\section{Analisis Deskriptif Kualitatif}

Analisis deskriptif kualitatif dimaksudkan untuk mendapatkan gambaran atau deskripsi mengenai tanggapan dari pegawai mengenai kemampuan intelektual dan disiplin kerja terhadap kinerja pegawai Kantor Kecamatan Siantar Sitalasari Kota Pematangsiantar.

\section{Gambaran Kemampuan Intelektual pada Kantor Kecamatan Siantar Sitalasari Kota Pematangsiantar}

Kemampuan intelektual merupakan salah satu faktor penting dan berpengaruh terhadap keberhasilan pegawai karena di dalamnya terdapat berbagai potensi kecakapan, keterampilan serta potensi lain yang mempengaruhi hasil yang dicapai:

Tabel 4. Rekapitulasi Jawaban Responden Mengenai Kemampuan Intelektual

\begin{tabular}{|c|c|c|c|c|c|c|c|c|}
\hline \multirow[b]{2}{*}{ No. } & \multirow[b]{2}{*}{ Pertanyaan } & \multicolumn{5}{|c|}{ Jawaban } & \multirow{2}{*}{$\begin{array}{l}\text { Nilai } \\
\text { Rata- } \\
\text { rata }\end{array}$} & \multirow{2}{*}{$\begin{array}{c}\text { Kriteria } \\
\text { Jawaban }\end{array}$} \\
\hline & & SB & B & CB & TB & STB & & \\
\hline \multicolumn{9}{|c|}{ A. Kemahiran Numerik } \\
\hline 1 & $\begin{array}{l}\text { Bagaimana tingkat } \\
\text { kemampuan anda dalam } \\
\text { berhitung dengan tepat? }\end{array}$ & 9 & 24 & 13 & 0 & 0 & 3,91 & Baik \\
\hline 2 & $\begin{array}{l}\text { Bagaimana tingkat } \\
\text { kemampuan anda dalam } \\
\text { berhitung dengan cepat? }\end{array}$ & 9 & 18 & 19 & 0 & 0 & 3,78 & Baik \\
\hline 3 & $\begin{array}{l}\text { Bagaimana kemampuan anda } \\
\text { dalam mengerjakan tugas? }\end{array}$ & 13 & 19 & 14 & 0 & 0 & 3,98 & Baik \\
\hline \multicolumn{9}{|c|}{ B. $\quad$ Kemampuan Verbal } \\
\hline 4 & $\begin{array}{l}\text { Bagaimana kemampuan anda } \\
\text { dalam memahami apa yang } \\
\text { dibaca? }\end{array}$ & 2 & 16 & 24 & 4 & 0 & 3,35 & $\begin{array}{c}\text { Cukup } \\
\text { Baik }\end{array}$ \\
\hline 5 & $\begin{array}{l}\text { Bagaimana kemampuan anda } \\
\text { dalam memahami apa yang } \\
\text { didengar? }\end{array}$ & 2 & 15 & 21 & 7 & 1 & 3,22 & $\begin{array}{l}\text { Cukup } \\
\text { Baik }\end{array}$ \\
\hline 6 & $\begin{array}{l}\text { Bagaimana kemampuan anda } \\
\text { dalam menyampaikan } \\
\text { pendapat? }\end{array}$ & 2 & 14 & 24 & 5 & 1 & 3,24 & $\begin{array}{l}\text { Cukup } \\
\text { Baik }\end{array}$ \\
\hline \multicolumn{9}{|c|}{ C. $\quad$ Kecepatan Perseptual } \\
\hline 7 & $\begin{array}{l}\text { Bagaimana kemampuan anda } \\
\text { dalam mengenali kemiripan } \\
\text { suatu permasalahan? }\end{array}$ & 15 & 19 & 12 & 0 & 0 & 4,07 & Baik \\
\hline 8 & $\begin{array}{l}\text { Bagaimana kemampuan anda } \\
\text { berpikir dalam menyelesaikan } \\
\text { tugas? }\end{array}$ & 18 & 16 & 12 & 0 & 0 & 4,13 & Baik \\
\hline 9 & $\begin{array}{l}\text { Bagaimana kemampuan anda } \\
\text { dalam mengidentifikasi } \\
\text { perbedaan suatu } \\
\text { permasalahan? }\end{array}$ & 15 & 19 & 12 & 0 & 0 & 4,07 & Baik \\
\hline
\end{tabular}




\begin{tabular}{|c|c|c|c|c|c|c|c|c|}
\hline D. & Penalaran Induktif & & & & & & & \\
\hline 10 & $\begin{array}{l}\text { Bagaimana kemampuan anda } \\
\text { dalam mengenali suatu urutan } \\
\text { permasalahan yang logis? }\end{array}$ & 13 & 21 & 12 & 0 & 0 & 4,02 & Baik \\
\hline 11 & $\begin{array}{l}\text { Bagaimana usaha yang anda } \\
\text { lakukan dalam } \\
\text { mengidentifikasi masalah? }\end{array}$ & 8 & 24 & 14 & 0 & 0 & 3,87 & Baik \\
\hline 12 & $\begin{array}{l}\text { Bagaimana kemampuan anda } \\
\text { dalam menyelesaikan suatu } \\
\text { permasalahan yang ada? }\end{array}$ & 13 & 15 & 18 & 0 & 0 & 3,89 & Baik \\
\hline E. & Penalaran Deduktif & & & & & & & \\
\hline 13 & $\begin{array}{l}\text { Bagaimana kemampuan } \\
\text { logika anda dalam menilai } \\
\text { suatu permasalahan? }\end{array}$ & 2 & 11 & 28 & 4 & 1 & 3,20 & $\begin{array}{c}\text { Cukup } \\
\text { Baik }\end{array}$ \\
\hline 14 & $\begin{array}{l}\text { Bagaimana kecakapan anda } \\
\text { dalam menjalankan tugas? }\end{array}$ & 3 & 13 & 23 & 5 & 2 & 3,22 & $\begin{array}{c}\text { Cukup } \\
\text { Baik }\end{array}$ \\
\hline 15 & $\begin{array}{l}\text { Bagaimana kemampuan anda } \\
\text { dalam bekerja secara } \\
\text { fleksibel? }\end{array}$ & 2 & 14 & 24 & 4 & 2 & 3,22 & $\begin{array}{c}\text { Cukup } \\
\text { Baik }\end{array}$ \\
\hline F. & Visualisasi Ruangan & & & & & & & \\
\hline 16 & $\begin{array}{l}\text { Bagaimana kemampuan anda } \\
\text { dalam membayangkan suatu } \\
\text { masalah yang terjadi? }\end{array}$ & 17 & 16 & 13 & 0 & 0 & 4,09 & Baik \\
\hline 17 & $\begin{array}{l}\text { Bagaimana kemampuan anda } \\
\text { membayangkan suatu objek } \\
\text { dalam suatu ruangan? }\end{array}$ & 17 & 15 & 13 & 1 & 0 & 4,04 & Baik \\
\hline 18 & $\begin{array}{l}\text { Bagaimana kemampuan anda } \\
\text { membayangkan suatu objek, } \\
\text { seandaianya posisi dalam } \\
\text { ruang diubah? }\end{array}$ & 15 & 17 & 12 & 2 & 0 & 3,98 & Baik \\
\hline G. & Memori & & & & & & & \\
\hline 19 & $\begin{array}{l}\text { Bagaimana kemampuan anda } \\
\text { dalam mengenang kembali } \\
\text { pengalaman kerja? }\end{array}$ & 17 & 18 & 11 & 0 & 0 & 4,13 & Baik \\
\hline 20 & $\begin{array}{l}\text { Bagaimana kemampuan anda } \\
\text { mengingat kesalahan masa } \\
\text { lalu sebagai pembelajaran? }\end{array}$ & 19 & 15 & 12 & 0 & 0 & 4,15 & Baik \\
\hline 21 & $\begin{array}{l}\text { Bagaimana memori anda } \\
\text { dalam mengingat suatu } \\
\text { pekerjaan? }\end{array}$ & 18 & 15 & 13 & 0 & 0 & 4,11 & Baik \\
\hline \multicolumn{2}{|c|}{ Total Jawaban } & 229 & 354 & 344 & 32 & 7 & $\mathbf{3 , 7 9}$ & \multirow{3}{*}{ Baik } \\
\hline Tota & Bobot & 1145 & 1416 & 1032 & 64 & 7 & 3664 & \\
\hline \multicolumn{2}{|c|}{ Persentase $(\%)$} & 31,25 & 38,65 & 28,17 & 1,75 & $\mathbf{0 , 1 8}$ & 100 & \\
\hline
\end{tabular}

Sumber: hasil pengolahan data kuesioner (2019)

Secara keseluruhan, hasil dari kuesioner kemampuan intelektual memperoleh nilai ratarata 3,79 dengan kriteria baik. Nilai rata-rata tertinggi adalah 4,15 dengan kriteria jawaban baik untuk dimensi memori pada indikator kemampuan mengingat kesalahan masa lalu sebagai pembelajaran. Sedangkan nilai rata-rata terendah adalah 3,20 dengan kriteria jawaban cukup baik untuk dimensi penalaran deduktif pada indikator kemampuan logika dalam menilai permasalahan. 


\section{Gambaran Disiplin pada Kantor Kecamatan Siantar Sitalasari Kota Pematangsiantar}

Disiplin kerja bagian dari fungsi operasioanl MSDM yang terpenting karna semakin baik disiplin pegawai, semakin tinggi prestasi kerja yang dicapainya. Tanpa disiplin pegawai yang baik, sulit bagi suatu organisasi untuk mencapai hasil yang optimal. Secara terminilogis, kata disiplin berasal dari kata "Disciplina" yang berarti pengajaran, pelatihan, dan sebaginya.

Tabel 5. Rekapitulasi Jawaban Responden Mengenai Disiplin

\begin{tabular}{|c|c|c|c|c|c|c|c|c|}
\hline \multirow[b]{2}{*}{ No. } & \multirow[b]{2}{*}{ Pertanyaan } & \multicolumn{5}{|c|}{ Jawaban } & \multirow{2}{*}{$\begin{array}{l}\text { Nilai } \\
\text { Rata- } \\
\text { rata }\end{array}$} & \multirow{2}{*}{$\begin{array}{l}\text { Kriteria } \\
\text { Jawaban }\end{array}$} \\
\hline & & SB & B & CB & TB & STB & & \\
\hline A. & Menjalankan Kewajiban & & & & & & & \\
\hline 1 & $\begin{array}{l}\text { Bagaimana anda dalam } \\
\text { mengucapkan sumpah janji PNS? }\end{array}$ & 11 & 20 & 15 & 0 & 0 & 3,91 & Baik \\
\hline 2 & $\begin{array}{lcr}\text { Bagaimana } & \text { anda } & \text { dalam } \\
\text { mengucapkan } & \text { sumpah } & \text { janji } \\
\text { jabatan? } & & \end{array}$ & 9 & 20 & 17 & 0 & 0 & 3,83 & Baik \\
\hline 3 & $\begin{array}{l}\text { Bagaimana tingkat kesetiaan dan } \\
\text { ketaatan anda kepada pancasila? }\end{array}$ & 13 & 18 & 15 & 0 & 0 & 3,96 & Baik \\
\hline 4 & $\begin{array}{l}\text { Bagaimana anda dalam menaati } \\
\text { segala peraturan perundang- } \\
\text { undangan? }\end{array}$ & 12 & 16 & 18 & 0 & 0 & 3,87 & Baik \\
\hline 5 & $\begin{array}{l}\text { Bagaimana anda dalam } \\
\text { melaksanakan tugas kedinasan? }\end{array}$ & 4 & 7 & 27 & 6 & 2 & 3,11 & $\begin{array}{l}\text { Cukup } \\
\text { Baik }\end{array}$ \\
\hline 6 & $\begin{array}{l}\text { Bagaimana } \begin{array}{c}\text { anda } \\
\text { menjunjung } \\
\text { negara? }\end{array} \text { tinggi kehormatan } \\
\end{array}$ & 11 & 22 & 13 & 0 & 0 & 3,96 & Baik \\
\hline 7 & $\begin{array}{lrr}\text { Bagaimana } & \text { anda } \quad \text { dalam } \\
\text { mengutamakan } & \text { kepentingan } \\
\text { Negara? } & \\
\end{array}$ & 12 & 21 & 13 & 0 & 0 & 3,98 & Baik \\
\hline 8 & $\begin{array}{l}\text { Bagaimana anda dalam } \\
\text { memegang rahasia jabatan? }\end{array}$ & 13 & 21 & 12 & 0 & 0 & 4,02 & Baik \\
\hline 9 & $\begin{array}{l}\text { Bagaimana anda dalam bekerja } \\
\text { dengan jujur? }\end{array}$ & 3 & 30 & 13 & 0 & 0 & 3,78 & Baik \\
\hline 10 & \begin{tabular}{lr} 
Bagaimana & \multicolumn{2}{c}{ anda } & dalam \\
melaporkan jika mengetahui \\
apabila ada hal yang \\
membahyakan negara?
\end{tabular} & 8 & 18 & 20 & 0 & 0 & 3,74 & Baik \\
\hline 11 & $\begin{array}{l}\text { Bagaimana anda dalam menaati } \\
\text { ketentuan jam kerja? }\end{array}$ & 8 & 9 & 19 & 7 & 3 & 3,26 & $\begin{array}{l}\text { Cukup } \\
\text { Baik }\end{array}$ \\
\hline 12 & $\begin{array}{l}\text { Bagaimana anda dalam mencapai } \\
\text { sasaran kerja yang ditetapkan? }\end{array}$ & 8 & 9 & 19 & 6 & 4 & 3,24 & $\begin{array}{l}\text { Cukup } \\
\text { Baik }\end{array}$ \\
\hline 13 & $\begin{array}{l}\text { Bagaimana anda dalam } \\
\text { memelihara barang-barang milik } \\
\text { negara? }\end{array}$ & 8 & 23 & 14 & 1 & 0 & 3,83 & Baik \\
\hline 14 & $\begin{array}{l}\text { Bagaimana anda dalam } \\
\text { memberikan pelayanan yang baik } \\
\text { kepada masyarakat? }\end{array}$ & 12 & 20 & 14 & 0 & 0 & 3,96 & Baik \\
\hline 15 & $\begin{array}{lcc}\text { Bagaimana anda } & \text { dalam } \\
\text { membimbing bawahan } & \text { dalam } \\
\text { melaksanakan tugas? } & \\
\end{array}$ & 11 & 13 & 22 & 0 & 0 & 3,76 & Baik \\
\hline 16 & $\begin{array}{l}\text { Bagaimana anda dalam } \\
\text { memberikan kesempatan kepada } \\
\text { bawahan untuk mengembangkan } \\
\text { karir? }\end{array}$ & 14 & 14 & 18 & 0 & 0 & 3,91 & Baik \\
\hline 17 & $\begin{array}{l}\text { Bagaimana anda dalam menaati } \\
\text { peraturan kedinasan? }\end{array}$ & 4 & 7 & 25 & 6 & 4 & 3,02 & $\begin{array}{l}\text { Cukup } \\
\text { Baik }\end{array}$ \\
\hline
\end{tabular}




\begin{tabular}{|c|c|c|c|c|c|c|c|c|}
\hline B. & Menjauhi Larangan & & & & & & & \\
\hline 18 & $\begin{array}{l}\text { Bagaimana sikap anda untuk tidak } \\
\text { menyalahgunakan wewenang? }\end{array}$ & 15 & 14 & 16 & 1 & 0 & 3,93 & Baik \\
\hline 19 & $\begin{array}{l}\text { Bagaimana sikap anda untuk tidak } \\
\text { menjadi perantara dalam } \\
\text { mendapatkan keuntungan? }\end{array}$ & 2 & 10 & 30 & 2 & 2 & 3,17 & $\begin{array}{l}\text { Cukup } \\
\text { Baik }\end{array}$ \\
\hline 20 & $\begin{array}{l}\text { Bagaimana sikap anda untuk tidak } \\
\text { bekerja dengan negara lain tanpa } \\
\text { izin pemerintah? }\end{array}$ & 10 & 19 & 17 & 0 & 0 & 3,85 & Baik \\
\hline 21 & $\begin{array}{l}\text { Bagaimana sikap anda untuk tidak } \\
\text { bekerja pada perusahaan asing? }\end{array}$ & 10 & 19 & 17 & 0 & 0 & 3,85 & Baik \\
\hline 22 & $\begin{array}{l}\text { Bagaimana sikap anda untuk tidak } \\
\text { memiliki barang-barang milik } \\
\text { negara dengan cara tidak sah? }\end{array}$ & 12 & 21 & 13 & 0 & 0 & 3,98 & Baik \\
\hline 23 & $\begin{array}{l}\text { Bagaimana sikap anda untuk tidak } \\
\text { melakukan kegiatan bersama } \\
\text { dengan atasan untuk kepentingan } \\
\text { pribadi? }\end{array}$ & 5 & 10 & 24 & 5 & 2 & 3,24 & $\begin{array}{l}\text { Cukup } \\
\text { Baik }\end{array}$ \\
\hline 24 & $\begin{array}{l}\text { Bagaimana sikap anda untuk tidak } \\
\text { memberikan hadiah pada } \\
\text { seseorang untuk diangkat dalam } \\
\text { jabatan? }\end{array}$ & 9 & 20 & 17 & 0 & 0 & 3,83 & Baik \\
\hline 25 & $\begin{array}{l}\text { Bagaimana sikap anda untuk tidak } \\
\text { menerima hadiah yang } \\
\text { berhubungan dengan jabatan? }\end{array}$ & 9 & 20 & 17 & 0 & 0 & 3,83 & Baik \\
\hline 26 & $\begin{array}{l}\text { Bagaimana sikap anda untuk tidak } \\
\text { bertindak sewenang-wenang pada } \\
\text { bawahan? }\end{array}$ & 10 & 21 & 15 & 0 & 0 & 3,89 & Baik \\
\hline 27 & $\begin{array}{l}\text { Bagaimana sikap anda untuk tidak } \\
\text { memberikan pelayanan kepada } \\
\text { masyarakat? }\end{array}$ & 4 & 18 & 24 & 0 & 0 & 3,57 & Baik \\
\hline 28 & $\begin{array}{l}\text { Bagaimana sikap anda untuk tidak } \\
\text { menghalangi berjalannya tugas } \\
\text { kedinasan? }\end{array}$ & 10 & 23 & 12 & 1 & 0 & 3,91 & Baik \\
\hline 29 & $\begin{array}{l}\text { Bagaimana sikap anda untuk tidak } \\
\text { menjadi peserta kampanye dengan } \\
\text { menggunakan atribut PNS? }\end{array}$ & 9 & 20 & 15 & 2 & 0 & 3,78 & Baik \\
\hline 30 & $\begin{array}{l}\text { Bagaimana sikap anda untuk tidak } \\
\text { membuat keputusan yang } \\
\text { menguntungkan salah satu calon } \\
\text { peserta pemilu? }\end{array}$ & 11 & 16 & 17 & 2 & 0 & 3,78 & Baik \\
\hline 31 & $\begin{array}{l}\text { Bagaimana sikap anda untuk tidak } \\
\text { mendukung calon anggota dewan } \\
\text { menggunakan fasilitas negara? }\end{array}$ & 12 & 15 & 18 & 1 & 0 & 3,83 & Baik \\
\hline 32 & $\begin{array}{l}\text { Bagaimana sikap anda untuk } \\
\text { tidak mendukung calon peserta } \\
\text { pemilu mengunakan fasilitas } \\
\text { negara? }\end{array}$ & 14 & 19 & 12 & 1 & 0 & 4,00 & Baik \\
\hline \multicolumn{2}{|c|}{ Total Jawaban } & 303 & 553 & 558 & 41 & 17 & 3,74 & \multirow{3}{*}{ Baik } \\
\hline \multicolumn{2}{|c|}{ Total Bobot } & 1515 & 2212 & 1674 & 82 & 17 & 5500 & \\
\hline \multicolumn{2}{|c|}{ Persentase (\%) } & 27,54 & 40,22 & 30,44 & 1,49 & $\mathbf{0 , 3 1}$ & 100 & \\
\hline
\end{tabular}

Sumber: hasil pengolahan kuesioner (2019)

Dari total jawaban responden mengenai disiplin nilai rata-rata sebesar 3,74 dengan kriteria jawaban baik. Kemudian nilai rata-rata tertinggi 4,02 dengan kriteria jawaban baik untuk dimensi menjalankan kewajiban pada indikator memegang rahasia jabatan. Sedangkan nilai rata-rata terendah sebesar 3,02 dengan kriteria jawaban cukup baik untuk dimensi menjalankan kewajiban pada indikator dalam menaati peraturan kedinasan. 


\section{Gambaran Kinerja Pegawai pada Kantor Kecamatan Siantar Sitalasari Kota Pematangsiantar}

Kinerja merupakan suatu keadaan yang harus diketahui mengenai tingkat pencapaian suatu organisasi yang dihubungkan dengan visi organisasi. Kinerja pegawai pada Kantor Kecamatan Siantar Sitalasari Kota Pematangsiantar diukur melalui dua dimensi yaitu sasaran kerja pegawai dan perilaku kerja, Berikut ini ditampilkan tabel mengenai kinerja pegawai yang terjadi pada Kota Pematangsiantar:

Tabel 6. Rekapitulasi Jawaban Responden mengenai Kinerja Pegawai

\begin{tabular}{|c|c|c|c|c|c|c|c|c|}
\hline \multirow{2}{*}{ No. } & \multirow{2}{*}{ Pertanyaan } & \multicolumn{5}{|c|}{ Jawaban } & \multirow{2}{*}{$\begin{array}{l}\text { Nilai } \\
\text { Rata- } \\
\text { rata }\end{array}$} & \multirow{2}{*}{$\begin{array}{l}\text { Kriteria } \\
\text { Jawaban }\end{array}$} \\
\hline & & SB & B & CB & TB & STB & & \\
\hline \multicolumn{9}{|c|}{ A. $\quad$ Sasaran Kinerja Pegawai } \\
\hline 1 & $\begin{array}{l}\text { Bagaimana pegawai } \\
\text { menangani volume pekerjaan } \\
\text { yang luar biasa banyak? }\end{array}$ & 2 & 15 & 22 & 6 & 1 & 3,24 & $\begin{array}{l}\text { Cukup } \\
\text { Baik }\end{array}$ \\
\hline 2 & $\begin{array}{l}\text { Bagaimana } \\
\begin{array}{l}\text { pencapaian } \\
\text { pegawai? }\end{array}\end{array}$ & 2 & 16 & 22 & 4 & 2 & 3,26 & $\begin{array}{l}\text { Cukup } \\
\text { Baik }\end{array}$ \\
\hline 3 & $\begin{array}{l}\text { Bagaimana tingkat ketelitian } \\
\text { pegawai dalam } \\
\text { menyelesaikan tugas? }\end{array}$ & 12 & 27 & 7 & 0 & 0 & 4,11 & Baik \\
\hline 4 & $\begin{array}{l}\text { Bagaimana pegawai dalam } \\
\text { bekerja sesuai standar yang } \\
\text { ditentukan? }\end{array}$ & 11 & 28 & 7 & 0 & 0 & 4,09 & Baik \\
\hline 5 & $\begin{array}{l}\text { Bagaimana pegawai dalam } \\
\text { menyelesaikan pekerjaan } \\
\text { dengan tepat waktu? }\end{array}$ & 2 & 12 & 23 & 5 & 4 & 3,07 & $\begin{array}{l}\text { Cukup } \\
\text { Baik }\end{array}$ \\
\hline 6 & $\begin{array}{l}\text { Bagaimana tingkat efisiensi } \\
\text { waktu pegawai dalam } \\
\text { menyelesaikan pekerjaan? }\end{array}$ & 2 & 14 & 24 & 6 & 0 & 3,26 & $\begin{array}{l}\text { Cukup } \\
\text { Baik }\end{array}$ \\
\hline 7 & $\begin{array}{l}\text { Bagaimana jumlah anggaran } \\
\text { yang diberikan kepada } \\
\text { pegawai } \\
\text { menyelesaikan pekerjaan? }\end{array}$ & 10 & 25 & 11 & 0 & 0 & 3,98 & $\begin{array}{l}\text { Cukup } \\
\text { Baik }\end{array}$ \\
\hline 8 & $\begin{array}{l}\text { Bagaimana kemampuan } \\
\text { pegawai dalam } \\
\text { mengalokasikan biaya? }\end{array}$ & 8 & 23 & 15 & 0 & 0 & 3,85 & Baik \\
\hline B. & Perilaku Kerja & & & & & & & \\
\hline 9 & $\begin{array}{l}\text { Bagaimana tingkat pelayanan } \\
\text { yang anda berikan? }\end{array}$ & 6 & 23 & 17 & 0 & 0 & 3,76 & Baik \\
\hline 10 & $\begin{array}{l}\text { Bagaimana } \\
\text { pencapaian target pelayanan } \\
\text { pegawai? }\end{array}$ & 2 & 10 & 27 & 7 & 0 & 3,15 & $\begin{array}{l}\text { Cukup } \\
\text { Baik }\end{array}$ \\
\hline 11 & $\begin{array}{l}\text { Bagaimana sikap dan perilaku } \\
\text { pegawai saat memberikan } \\
\text { pelayanan? }\end{array}$ & 16 & 15 & 15 & 0 & 0 & 4,02 & Baik \\
\hline 12 & $\begin{array}{l}\text { Bagaimana etika pegawai } \\
\text { dalam instansi? }\end{array}$ & 13 & 14 & 19 & 0 & 0 & 3,87 & Baik \\
\hline 13 & $\begin{array}{l}\text { Bagaimana kemampuan } \\
\text { pegawai dalam instansi? }\end{array}$ & 13 & 16 & 17 & 0 & 0 & 3,91 & Baik \\
\hline 14 & $\begin{array}{l}\text { Bagaimana konsistensi } \\
\text { pegawai dalam bekerja? }\end{array}$ & 2 & 13 & 26 & 4 & 1 & 3,24 & $\begin{array}{l}\text { Cukup } \\
\text { Baik }\end{array}$ \\
\hline 15 & $\begin{array}{l}\text { Bagiman sikap pegawai dalam } \\
\text { instansi? }\end{array}$ & 14 & 19 & 13 & 0 & 0 & 4,02 & Baik \\
\hline
\end{tabular}




\begin{tabular}{|c|c|c|c|c|c|c|c|c|}
\hline \multirow[b]{2}{*}{ No. } & \multirow[b]{2}{*}{ Pertanyaan } & \multicolumn{5}{|c|}{ Jawaban } & \multirow{2}{*}{$\begin{array}{l}\text { Nilai } \\
\text { Rata- } \\
\text { rata }\end{array}$} & \multirow{2}{*}{$\begin{array}{l}\text { Kriteria } \\
\text { Jawaban }\end{array}$} \\
\hline & & SB & B & CB & TB & STB & & \\
\hline 16 & $\begin{array}{l}\text { Bagaimana tingkat kesediaan } \\
\text { pegawai melakukan pekerjaan } \\
\text { tanpa diperintah atasan? }\end{array}$ & 13 & 18 & 15 & 0 & 0 & 3,96 & Baik \\
\hline 17 & $\begin{array}{l}\text { Bagaimana kewajiban } \\
\text { pegawai dalam melaksanakan } \\
\text { tugasnya? }\end{array}$ & 2 & 14 & 24 & 3 & 3 & 3,20 & $\begin{array}{l}\text { Cukup } \\
\text { Baik }\end{array}$ \\
\hline 18 & $\begin{array}{l}\text { Bagaimana kedisiplinan } \\
\text { pegawai dalam instansi? }\end{array}$ & 18 & 14 & 14 & 0 & 0 & 4,09 & Baik \\
\hline 19 & $\begin{array}{l}\text { Bagaimana hubungan } \\
\text { kerjasama antara pegawai? }\end{array}$ & 15 & 18 & 12 & 1 & 0 & 4,02 & Baik \\
\hline 20 & $\begin{array}{l}\text { Bagaimana hubungan } \\
\text { pegawai dengan atasan? }\end{array}$ & 16 & 15 & 14 & 1 & 0 & 4,00 & Baik \\
\hline \multicolumn{2}{|c|}{ Total Jawaban } & 179 & 349 & 344 & 37 & 11 & 3,70 & \multirow{3}{*}{ Baik } \\
\hline \multicolumn{2}{|c|}{ Total Bobot } & 895 & 1396 & 1032 & 74 & 11 & 3408 & \\
\hline \multicolumn{2}{|c|}{ Persentase (\%) } & 26,26 & 40,96 & 30,28 & 2,17 & $\mathbf{0 , 3 2}$ & 100 & \\
\hline
\end{tabular}

Sumber: hasil pengolahan data kuesioner (2019)

Dari total jawaban responden mengenai dimensi sasaran kinerja pegawai dan perilaku kerja mendapat nilai rata-rata sebesar 3,70 dengan kriteria jawaban baik. Kemudian nilai ratarata tertinggi 4,11 dengan kriteria jawaban baik untuk dimensi sasaran kinerja pegawai pada indikator kualitas tingkat ketelitian pegawai . Sedangkan nilai rata-rata terendah sebesar 3,07 dengan kriteria jawaban cukup baik untuk dimensi sasaran kerja pegawai pada indikator tepat waktu.

\section{Analisis Deskriptif Kuantitatif}

\section{Analisis Regresi Liner Sederhana}

Untuk menganalisis pengaruh kemampuan intelektual dan disiplin kerja terhadap kinerja pegawai Kantor Kecamatan Siantar Sitalasari Kota Pematangsiantar. Analisis data dalam penelitian ini menggunakan analisis regresi linier berganda. Analisis regresi linier berganda yang dimaksud dapat disajikan pada tabel berikut ini:

Tabel 7. Hasil Regresi Linier Sederhana

\begin{tabular}{|c|c|c|c|}
\hline \multirow{2}{*}{ Model } & \multicolumn{2}{|c|}{ Unstandardized Coefficients } & \multirow{2}{*}{$\begin{array}{c}\begin{array}{c}\text { Standardized } \\
\text { Coefficients }\end{array} \\
\text { Beta }\end{array}$} \\
\hline & $\boldsymbol{B}$ & Std. Error & \\
\hline 1 (Constant $)$ & 15,759 & 7,342 & \\
\hline $\begin{array}{l}\text { Kemampuan Intelektual } \\
\text { (X1) }\end{array}$ & ,367 & , 134 & ,396 \\
\hline Disiplin Kerja ( X2) & ,244 & ,81 & ,434 \\
\hline
\end{tabular}

a. Dependent Variabel: Kinerja Pegawai

Sumber: hasil pengolahan kuesioner dengan SPSS versi 21 (2019)

Dari hasil pengolahan data pada tabel 7 di atas, diperoleh model persamaan $\hat{Y}=$ $15,759+0,367 \mathrm{X}_{1}+0,244 \mathrm{X}_{2}$, artinya terdapat pengaruh positif antara kemampuan intelekual 
dan disiplin kerja terhadap kinerja pegawai pada Kantor Kecamatan Siantar Sitalasari Kota Pematangsiantar.

\section{Analisi Korelasi dan Koefisien Determinan (KD)}

Perhitungan korelasi berupa derajat atau kedalaman hubungan fungsional yang menjelaskan hubungan antara perubah, dinyatakan dengan yang dinamakan korelasi yang sering disimbolkan dengan $r$, nilai $r$ dapat dihitung menggunakan SPSS versi 21. Hasil korelasi dan koefisien determinasi dapat dilihat pada tabel berikut ini:

Tabel 8. Hasil Koefisien Korelasi dan Koefisien Determinasi

\begin{tabular}{|l|r|r|r|r|}
\hline Model & $R$ & $R$ Square & Adjusted R Square & \multicolumn{2}{|l|}{ Std. Error of the Estimate } \\
\hline 1 &, 776 &, 602 &, 584 & 5,237 \\
\hline
\end{tabular}

a. Predictors: (Constant), Disiplin Kerja (X2), Kemampuan Intelektual ( X1)

b. Dependent Variable: Kinerja Pegawai (Y)

Sumber: hasil pengolahan kuesioner menggunakan SPSS versi 21 (2019)

Dari hasil korelasi pada tabel 5.9 di atas diperoleh nilai korelasi $(r)=0,776$ yang artinya terdapat hubungan yang kuat dan positif antara kemampuan intelektual, disiplin kerja dengan kinerja pegawai pada Kantor Kecamatan Siantar Sitalasari Kota Pematangsiantar, sesuai dengan kriteria korelasi.

Kemudian diperoleh nilai koefisien determinasi $(\mathrm{R})=0,602$ artinya tinggi rendahnya kinerja pegawai (Y) pada Kantor Kecamatan Siantar Sitalasari Kota Pematangsiantar sebesar 60,2\% dapat dijelaskan oleh kemampuan intelektual $\left(\mathrm{X}_{1}\right)$ dan disiplin kerja $\left(\mathrm{X}_{2}\right)$ sedangkan sisanya sebesar 39,8\% dipengaruhi oleh faktor lain seperti budaya organisasi, komunikasi, kompensasi, pengembangan karir, komitmen, gaya kepemimpinan, pelatihan, kepuasan kerja dan variabel lain yang tidak diteliti dalam penelitian ini.

\section{Uji Hipotesis}

Pengujian ini dilakukan secara parsial yaitu dilakukan untuk menentukan diterimanya atau ditolaknya hipotesis, pengujian hipotesis dilakukan untuk mengetahui apakah variabel kemampuan intelektual dan disiplin kerja yang di uji berpengaruh terhadap kinerja pegawai. Jika thitung $>$ ttabel atau signifikansi $\leq 0,05$ maka $\mathrm{H}_{0}$ ditolak. Untuk menguji kebenarannya maka dilakukan pengujian hipotesis dengan menggunakan program aplikasi SPSS versi 21 . 
Tabel 9. Perkiraan nilai $t_{\text {hitung }}$

\begin{tabular}{|ll|r|r|}
\hline \multicolumn{1}{|c|}{ Model } & \multicolumn{1}{|c|}{ S } & \multicolumn{2}{c|}{ Sig. } \\
\hline \multirow{4}{*}{1} & (Constant) & 2,146 &, 038 \\
& Kemampuan Intelektual & $\mathbf{2 , 7 4 0}$ &, 009 \\
& (X1) & $\mathbf{3 , 0 0 4}$ &, 004 \\
\hline
\end{tabular}

a. Dependent Variabel: Kinerja Pegawai

Sumber: hasil pengolahan kuesioner dengan SPSS versi 21 (2019)

Berdasarkan tabel 9 di atas, diperoleh nilai thitung pada variabel $\mathrm{X}_{1}$ (kemampuan intelektual) sebesar 2,740 > ttabel dengan df =n-k-1 (46-2-1=43) sebesar 2,017 atau taraf signifikan $0,009<\alpha 0,05$, maka $\mathrm{H}_{0}$ ditolak, artinya kemampuan intelektual berpengaruh positif dan signifikan terhadap kinerja pegawai pada Kantor Kecamatan Siantar Sitalasari Kota Pematangsiantar.Kemudian nilai thitung pada variabel $\mathrm{X}_{2}$ (Disiplin kerja) sebesar 3,004 > dari ttabel dengan $\mathrm{df}=\mathrm{n}-\mathrm{k}-1(46-2-1=43)$ sebesar 2,017 atau taraf signifikan 0,004 $<\alpha 0,05$, maka $\mathrm{H}_{0}$ ditolak, artinya Disiplin kerja berpengaruh positif dan signifikan terhadap kinerja pegawai pada Kantor Kecamatan Siantar Sitalasari Kota Pematangsiantar.

\section{Pengaruh Kemampuan Intelektual Terhadap Kinerja}

Seorang pegawai akan menghasilkan kinerja yang memuaskan apabila ia menyenangi pekerjaannya. Dengan adanya kecerdasan intelektual yang tinggi, maka kemampuan pegawai akan meningkat. Tinggi rendahnya kinerja pegawai dapat dilihat dari kemampuan pegawai dalam menyelesaikan tugas yang diberikan. Pegawai yang memiliki tingkat kecerdasan intelektual yang baik akan memiliki kemampuan yang baik pula dalam menjalankan tugasnya sehingga akan menghasilkan kinerja yang optimal. Berdasarkan hasil penelitian yang diperoleh pada pembahasan sebelumnya, dapat disimpulkan bahwa kemampuan intelektual berpengaruh positif dan signifikan terhadap kinerja. Hal ini sejalan dengan penelitian yang dilakukan oleh (Darmayanti, Bagia and Suwendra, 2014), (Muttaqiyathun, 2010), (Damanik, 2018), (Susi and Raden, 2013), yang menyatakan ada pengaruh kemampuan intelektual terhadap kinerja.

\section{Pengaruh Disiplin Kerja Terhadap Kinerja}

Pegawai akan berusaha sebaik-baiknya untuk menyelesaikan apa yang menjadi pekerjaannya sehingga tujuan organisasi dapat tercapai. Suatu pekerjaan akan terasa sangat menyenangkan apabila dipimpin oleh seorang pemimpin yang bijaksana dan dapat membimbing bawahannya dalam bekerja. Disiplin yang baik mencerminkan besarnya tanggungjawab seseorang terhadap tugas-tugas yang diberikan kepadanya. Hal ini mendorong gairah kerja, semangat kerja, dan terwujudnya tujuan perusahaan, pegawai serta masyarakat 
pada umumnya. Berdasarkan hasil penelitian yang diperoleh pada pembahasan sebelumnya, dapat disimpulkan bahwa disiplin kerja berpengaruh positif dan signifikan terhadap kinerja. Temuan tersebut mendukung penelitian sebelumnya yang dilakukan oleh (Mulyadi and Marliana, 2010), (Afianto and Utami, 2017), (Lie et al., 2019), (Isvandiari and Idris, 2018), (Pomalingo, Mandey and Uhing, 2015), (Pangarso and Susanti, 2016), yang menyatakan ada pengaruh disiplin kerja terhadap kinerja.

\section{PENUTUP}

Hasil analisis regresi linier berganda menunjukkan adanya pengaruh yang positif antara kemampuan intelektual, disiplin kerja dengan kinerja pegawai pada Kantor Kecamatan Siantar Sitalasari Kota Pematangsiantar.Hasil analisis korelasi menunjukkan hubungan yang sangat kuat dan positif antara kemampuan intelektual, disiplin kerja dengan kinerja pegawai. Sedangkan baik tidaknya kinerja pegawai dapat dijelaskan oleh kemampuan intelektual dan disiplin kerja sedangkan sisanya dipengaruhi oleh faktor lain yang tidak diteliti dalam penelitian ini. Hasil pengujian hipotesis secara parsial untuk variabel kemampuan intelektual dengan uji t $\mathrm{H}_{0}$ ditolak, artinya terdapat pengaruh yang positif dan signifikan antara variabel kemampuan intelektual terhadap kinerja pegawai pada Kantor Kecamatan Siantar Sitalasari Kota Pematangsiantar. Kemudian pengujian hipotesis secara parsial untuk variabel disiplin kerja dengan perolehan uji t maka $\mathrm{H} 0$ ditolak, artinya disiplin kerja berpengaruh positif dan signifikan terhadap kinerja pegawai pada Kantor Kecamatan Siantar Sitalasari Kota Pematangsiantar.

Untuk meningkatkan kemampuan intelektual yang ada pada pegawai Kantor Kecamatan Siantar Sitalasari Kota Pematangsiantar, sebaiknya pegawai membiasakan diri untuk lebih aktif mengungkapkan pendapatnya di dalam organisasi, mendapatkan pelatihan yang sesuai dengan jabatannya, serta membuat penjadwalan pengumpulan laporan agar mudah mengingat tugas yang harus segera diselesaikan. Untuk mengoptimalkan disiplin kerja, sebaiknya Kantor Kecamatan Siantar Sitalasari Kota Pematangsiantar diharapkan kepada setiap pihak, baik pegawai maupun pimpinan lebih menaati segala peraturan yang diterapkan di organisasi sehingga disiplin kerja pegawai dapat terjaga.Untuk meningkatkan kinerja pegawai pada Kantor Kecamatan Siantar Sitalasari Kota Pematangsiantar, sebaiknya pegawai lebih memperhatikan jadwal kerjanya agar kinerja yang dihasilkan mencapai target yang ditentukan, dan mengikuti standar operasi pelayanan yang ada. Sedangkan untuk organisasi, sebaiknya memberikan sanksi berupa surat peringatan yang tegas dan konsisten terhadap pegawai yang melanggar disiplin untuk memberikan efek jera. 


\section{DAFTAR PUSTAKA}

Afianto, I.D., and Utami, H.N. (2017). Pengaruh Disiplin Kerja Dan Komunikasi Organisasi Terhadap Kepuasan Kerja Dan Kinerja Karyawan (Studi pada Karyawan Divisi Marketing PT. Victory International Futures Kota Malang), Jurnal Administrasi Bisnis, 50 (6): 58-67.

Chamorro-Premuzic, T., Quiroga, M.A. and Colom, R. (2009). Intellectual competence and academic performance: A Spanish study, Learning and Individual Differences. Elsevier Inc., 19 (4): 486-491. doi: 10.1016/j.lindif.2009.05.002.

Damanik, B.E. (2018). Pengaruh Kemampuan Intelektual Dan Motivasi Kerja Terhadap Kinerja Guru, Idaarah: Jurnal Manajemen Pendidikan, 2 (2): 143. doi: 10.24252/idaarah.v2i2.6356.

Darmayanti, N.P., Bagia, I.W., and Suwendra, I.W. (2014). Berprestasi Terhadap Kinerja Pegawai Pada Perusahaan Daerah Air Minum (PDAM) Di Kabupaten Gianyar, $e$ Journal Bisma Universitas Pendidikan Ganesha, 2 (1): 1-10.

Goyal, A., and Akhilesh, K. (2008). Interplay Amonng Innovativeness, Cognitive Intelligence, Emotional Intelligence and Social Capital of Work Teams, Team Performance Management: An International Journal, 13 (7): 206-226. doi: 10.1108/13527590810860221.

Harlie, M. (2012). Pengaruh Disiplin Kerja, Motivasi dan Pengembangan Karier Terhadap Kinerja Pegawai Negeri Sipil Pada Pemerintah Kabupaten Tabalong di Tanjung Kalimantan Selatan, Jurnal Aplikasi Manajemen, 10 (4): 860-867.

Istiqomah, S.N., and Suhartini, S. (2016). Pengaruh disiplin kerja dan iklim komunikasi terhadap kinerja pegawai Dinas Perhubungan Kota Yogyakarta, dengan motivasi kerja sebagai variabel intervening, Jurnal Siasat Bisnis. doi: 10.20885/jsb.vol19.iss1.art8.

Isvandiari, A., and Idris, B. Al. (2018). Pengaruh Kepemimpinan Dan Disiplin Kerja Terhadap Kinerja Karyawan Pada PT Central Capital Futures Cabang Malang, Jurnal Ilmiah Bisnis dan Ekonomi Asia, 12 (1): 17-22. doi: 10.32812/jibeka.v12i1.7.

Lie, D. et al. (2019). The Impact of Work Discipline and Work Ethic on the Teacher Performance of Sultan Agung Pematangsiantar Private Middle School Teachers T.A. 2018/2019, International Journal of Business Studies, 3 (3): 125-135. doi: 10.32924/ijbs.v3i3.83.

Mulyadi, H., and Marliana, N. (2010). Pengaruh Motivasi Dan Disiplin Kerja Karyawan Terhadap Kinerja Karyawan Pada Departemen Weaving PT. Adetex Cabang Banjaran 
Kab. Bandung, Strategic: Jurnal Pendidikan Manajemen Bisnis, 10 (1): 40. doi: 10.17509/strategic.v10i1.1077.

Muttaqiyathun, A. (2010). Pengaruh kecerdasan emosional, kecerdasan intelektual dan kecerdasan spiritual terhadap kinerja dosen, Ekonomi Bisnis, 2 (2): 395-408.

Pangarso, A., and Susanti, P.I. (2016). Pengaruh Disiplin Kerja Terhadap Kinerja Pegawai Di Biro Pelayanan Sosial Dasar Sekretariat Daerah Provinsi Jawa Barat, Jurnal Manajemen Teori dan Terapan, 9 (2): 145-160. Available at: http://ejournal.unair.ac.id/index.php/JMTT/article/view/3019.

Pomalingo, R., Mandey, S. L., and Uhing, Y. (2015). Pengaruh disiplin kerja, kompetensi, dan motivasi terhadap kinerja pegawai pada kantor Badan Penanggulangan Bencana Daerah Provinsi Sulawesi Utara, Jurnal Berkala Ilmiah Efisiensi, 15 (5): 528-537.

Sahir, S. H. et al. (2020). Keterampilan Manajerial Efektif. Cetakan 1. Medan: Yayasan Kita Menulis.

Susi, H. and Raden, L. G. (2013). Pengaruh Kecerdasan Intelektual dan Kecerdasan Emosional Terhadap Kinerja Guru SMAN 8 Pekanbaru, Jurnal Ekonomi, 21 (4): 1-10.

Umbrasas, K. V. (2018). Low intellectual ability does not predict violent crime in a military forensic sample, Intelligence. Elsevier, 7 (1): 41-45. doi: 10.1016/j.intell.2018.10.003.

Widodo. (2012). Psikologi Belajar. Jakarta: Rineka Cipta.

Zainal, et. all. (2015). Manajemen Sumber Daya Manusia untuk Perusahaan. Edisi ketiga. Cetakan 7. Jakarta: Rajawali Pers. 